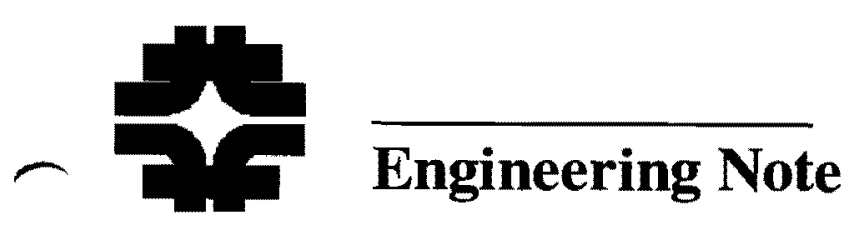

\title{
CALORIMETER PREAMPLIFIER HYBRID CIRCUIT TEST JIG
}

\author{
ENGINEERING NOTE
}

3823.121-EN-512

BENJAMIN M. ABRAHAM

APRIL 19, 1999 


\section{Benjamin M. Abraham Engineering Note}

Date: $\quad 10 / 30 / 98$

Rev Date: $\quad$ 10/29/98

Project: $\quad$ Calorimeter Preamplifier Hybrid Circuit Test Jig.

Doc. No: A981030A

Subject: $\quad$ Theory Of Operation

\section{Introduction:}

The purpose of the Calorimeter Preamplifier Hybrid Circuit is to do the initial amplification of the Calorimeter signals. The test jig consists of the following main blocks:

1- Main power supply, which converts $120 \mathrm{~V} \mathrm{AC}$ to the regulated $+15 \mathrm{~V},-15 \mathrm{~V}$, and $+5 \mathrm{~V}$ DC values.

2- LED display board

3- Zero insertion force board (ZIF) which includes:

a_ZIF socket.

b_U1 and S1 DIP switches, which are accessible to the vendor. They are used to select the desired detector capacitor which is applied to the input of the related preamp specie.

4-Electronic board which includes:

a_ Two NOR gates which are configured as a latch to eliminate the switch (Push-to-Test button) bounce.

b_ $+10 \mathrm{~V},-10 \mathrm{~V},-10 \mathrm{~V}$ ref, $-5.2 \mathrm{~V},+12 \mathrm{~V},+8 \mathrm{~V}$, and $-6 \mathrm{~V}$ voltage regulators.

$\mathrm{c}_{-}+15 \mathrm{~V},-15 \mathrm{~V}$, and $+5 \mathrm{~V}$ voltage window comparators.

$\mathrm{d}_{-}+12 \mathrm{~V},+8 \mathrm{~V}$, and $-6 \mathrm{~V}$ current window comparators.

e_ Digital logic

f_ Test pulse and trigger pulse.

g_Current source.

h_U26 DIP switch, which is accessible to the vendor. It is used to select the desired resistor value at the emitter of the current source. The selected resistor value depends on the device under test (DUT) category. There are three categories:

1- DUT with $5 \mathrm{pF}$ feedback capacitor includes preamplifier species: $\mathrm{A}, \mathrm{B}, \mathrm{C}$, and D.

2- DUT with $10 \mathrm{pF}$ feedback capacitor includes preamplifier species: $\mathrm{E}, \mathrm{F}, \mathrm{G}, \mathrm{Ha}, \mathrm{Hb}, \mathrm{Hc}$, $\mathrm{Hd}, \mathrm{He}, \mathrm{Hf}$, and $\mathrm{Hg}$.

3- DUT with $22 \mathrm{pF}$ feedback capacitor includes only one specie: I.

NOTE: THE FIRST TWO CATEGORIES ARE TESTED BY ONE TEST JIG AND THE THIRD CATEGORY BY ANOTHER TEST JIG CALLED I. THEREFOR THE ADVICE TO THE VENDOR 
The following diagram shows the test jig block diagram and its connection to the external equipment:

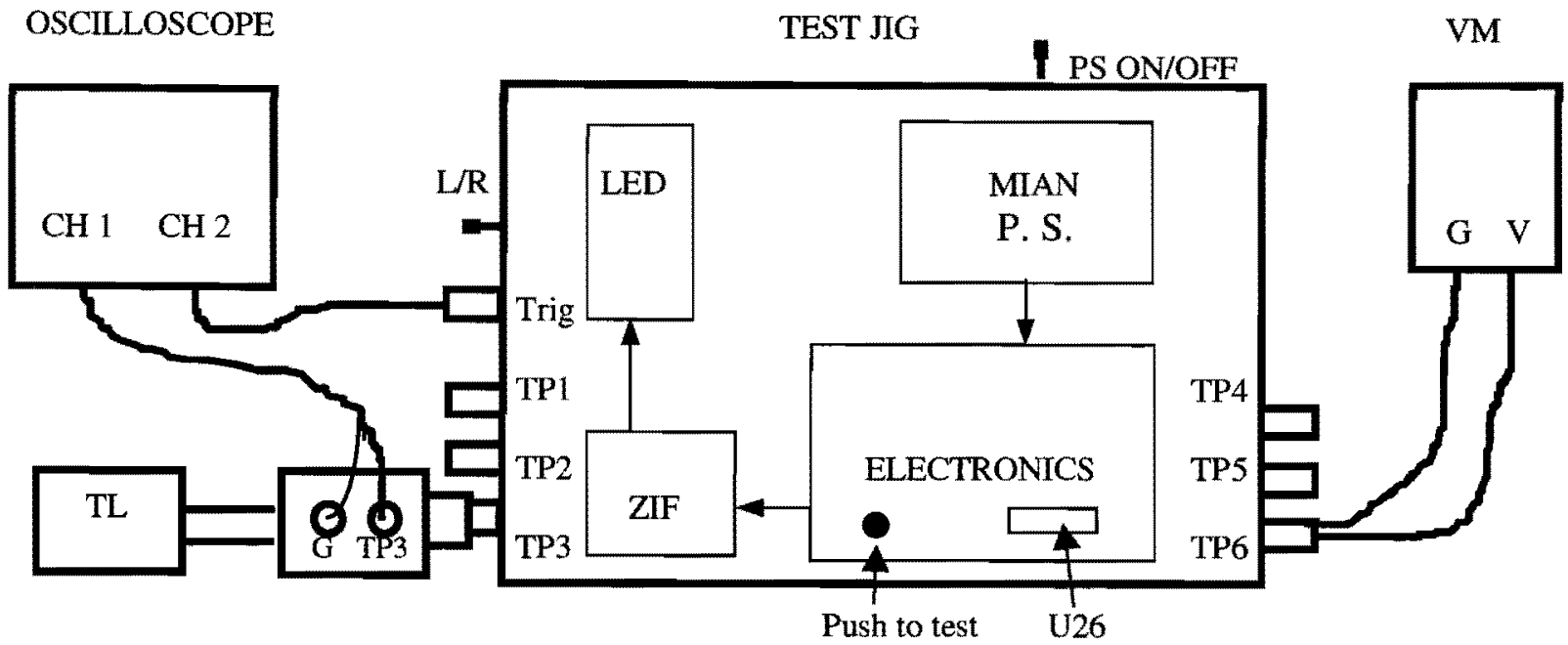

Note:

TP1, TP2, and TP3 are the outputs of the DUT for each of the first, second, and final stage respectively. TP4, TP5, and TP6 are the outputs for current measurements of each power rail, including $+12 \mathrm{~V},-6 \mathrm{~V}$, and $+8 \mathrm{~V}$ respectively.

$\mathrm{TL}$ is the terminal load used to terminate DUT output.

$\mathrm{L} / \mathrm{R}$ is the Local/Remote switch to switch the test jig to the desired mode of operation.

\section{Theory of operation:}

There are two ways in which the testing may be initiated, remotely or locally. If the remote operation is desired, an external TTL level signal must be provided to the test jig with the remote/local switch on the side of the test jig switched to remote. A logic high will initiate the test. A logic low will terminate the test. In the event that an external signal is connected to the test jig while local operation occurs, the local control takes precedence over remote control.

Once a DUT has been locked in the ZIF socket and the DIP switches are selected, the Push-toTest button may be depressed. Momentarily depressing the button will initiate a test with a minimum 400 $\mathrm{ms}$ duration. At the same time a PBCLOCK and PBLATCH pulses will be initiated and the power rails $+12 \mathrm{~V},+8 \mathrm{~V}$, and $-6 \mathrm{~V}$ will be ramped to full voltage. The time at which the power rails reach the full voltage is about $13 \mathrm{~ms}$ and it is synchronized with bypass capacitors placed on COMP input of U20 and $\mathrm{U} 22$ and on the output of $\mathrm{U} 23$ voltage regulators (see schematic \#2). The voltage rails are supplied to a 
$\pm 10 \%$ window comparator (see schematics $3,4, \& 5$ ). A red LED indicates the rail is below or above $10 \%$ of the design value. A green LED indicates the rail is within acceptable limits. For DUT with a $5 \mathrm{pF}$ and $10 \mathrm{pF}$ feed back capacitor, the $+12 \mathrm{~V}$ and $+8 \mathrm{~V}$ rails are current-regulated to $19 \mathrm{~mA}$ and $22 \mathrm{~mA}$ respectively and the $-6 \mathrm{~V}$ rail is short-circuit protected within the regulator. For DUT with a $22 \mathrm{pF}$ feed back capacitor the current regulation is the same as above except that the $+8 \mathrm{~V}$ rail is current regulated to $43 \mathrm{~mA}$. The power rails are supplied to the DUT via a $10 \Omega$ resistor. The voltage drop across this resistor is sensed by a differential amplifier AD620 and amplified by a gain of 10 (see schematics 6, 7, \& 8). An external BNC connection is provided from this point to allow for current measurements by the vendor. The current value for each rail is calculated by measuring the voltage value at this point and divided by $(10 * 10 \Omega)$. The next stage inverts and amplifies the voltage signal by a factor of 5 for $+12 \mathrm{~V}$ and $-6 \mathrm{~V}$ rails and by a factor of 1 for $+8 \mathrm{~V}$ rail. For DUT with $22 \mathrm{pF}$ feed back capacitor the amplification factors are same as above except that the amplification factor for $+8 \mathrm{~V}$ rail is a gain of 2 . An offset null potentiometer is provided between the AD620 and the inverting stage which eliminates device offset current errors. The inverted and amplified voltage is presented to two window comparators. One of them compares the inverted and amplified voltage to the low threshold point and the other one compares the inverted and amplified voltage to the high threshold point. If the inverted and amplified voltage is within the low and high threshold points, both the low and the high current LEDs illuminate green indicating the current is within acceptable limits. If the inverted and amplified voltage is below the low threshold point or above the high threshold point, the low current LED or the high current LED illuminates red, respectively, indicating the current is outside acceptable limits.

The following tables show:

1- The current ranges in respect to the designed target current.

2- The window current ranges that the window comparators are capable of handling.

For DUT With 5 pF Or 10 pF Feedback Capacitors

\begin{tabular}{|c|c|c|c|c|}
\hline \multicolumn{2}{|c|}{ Current Window Comparator } & $+8 \mathrm{~V}$ & $+12 \mathrm{~V}$ & $-6 \mathrm{~V}$ \\
\hline \multicolumn{2}{|l|}{ Target Current } & $20.45 \mathrm{~mA}$ & $9.25 \mathrm{~mA}$ & $10.4 \mathrm{~mA}$ \\
\hline \multicolumn{2}{|l|}{ Current Range } & $\pm 34.47 \%$ & $\pm 10.27 \%$ & $\pm 10.58 \%$ \\
\hline \multirow{2}{*}{$\begin{array}{l}\text { Window } \\
\text { Current Range }\end{array}$} & Low & $9 \mathrm{~mA}$ & $6 \mathrm{~mA}$ & $7 \mathrm{~mA}$ \\
\hline & High & $33 \mathrm{~mA}$ & $11 \mathrm{~mA}$ & $12 \mathrm{~mA}$ \\
\hline
\end{tabular}

For DUT With 22 pF Feedback Capacitor

\begin{tabular}{|c|c|c|c|c|}
\hline \multicolumn{2}{|c|}{ Current Window Comparator } & $+8 \mathrm{~V}$ & $+12 \mathrm{~V}$ & $-6 \mathrm{~V}$ \\
\hline \multicolumn{2}{|l|}{ Target Current } & $18.2 \mathrm{~mA}$ & $9.18 \mathrm{~mA}$ & $10.2 \mathrm{~mA}$ \\
\hline \multicolumn{2}{|l|}{ Current Range } & $\pm 10 \%$ & $\pm 10 \%$ & $\pm 10.58 \%$ \\
\hline \multirow{2}{*}{$\begin{array}{l}\text { Window } \\
\text { Current Range }\end{array}$} & Low & $8 \mathrm{~mA}$ & $6 \mathrm{~mA}$ & $7 \mathrm{~mA}$ \\
\hline & High & $24 \mathrm{~mA}$ & $11 \mathrm{~mA}$ & $13 \mathrm{~mA}$ \\
\hline
\end{tabular}


When the PBCLOCK pulse is initiated an 18 ms delay pulse is generated by U12:A (see schematic \#9). This $18 \mathrm{~ms}$ delay pulse is used to delay the test pulse to the DUT, and the current rails data to the LED board. This delay is needed for two purposes:

1- To make sure that the power rails $+12 \mathrm{~V},+8 \mathrm{~V}$. and $-6 \mathrm{~V}$ are ramped to the full voltage. So, that the DUT is stabilized on these full voltage rails before getting the test pulse.

2- To make sure that the current rails are stabilized. So, that the LED board will get the correct data.

As it is mentioned earlier, the power rails need about $13 \mathrm{~ms}$ to ramp up to the full voltage, but an addition of $5 \mathrm{~ms}$ is added to it to make it $18 \mathrm{~ms}$ which is the time needed for the DUT currents to stabilize.

When the PBCLOCK pulse is initiated a $268 \mathrm{~ms}$ delay in the trigger pulse is generated. $18 \mathrm{~ms}$ by U12:A and $250 \mathrm{~ms}$ by U40:A (see schematic \#12). This delay in the trigger pulse is needed to make sure that DUT output base line is stable.

To synchronize the trigger pulse with the rising edge of the DUT output, two AND gates are used to AND the output of the Crystal oscillator U24 with DFF output U42:A:5 and with DFF output U42:B:9 (see schematic \#12).

If the DUT passes the supply current test (the summation signal is satisfied in schematic \#9), then a $1 \mathrm{~ms}$ test pulse period is generated by U25:A (see schematic \#12). U27 is used to convert the generated test pulse from TTL level To MECL level. This MECL level is presented to the current source circuit to generate an amount of current (Ie) to charge the DUT. The amount of current produced depends on the DUT categories. The amount of current produced is controlled by the test pulse width (Tw) generated by U25:A and by the resistor value (Re) at the emitter of Q5 and Q6. The following table shows the Ie values and the corresponded $\mathrm{Tw}$, and Re values.

\begin{tabular}{|l|c|c|c|}
\hline DUT Categories & Ie & Tw & Re \\
\hline 5 pF Feedback Cap. & $75 \mu \mathrm{A}$ & $200 \mathrm{~ns}$ & $44.89 \mathrm{~K} \Omega$ \\
\hline 10 pF Feedback Cap. & $175 \mu \mathrm{A}$ & $200 \mathrm{~ns}$ & $22.95 \mathrm{~K} \Omega$ \\
\hline $22 \mathrm{pF}$ Feedback Cap. & $1320 \mu \mathrm{A}$ & $50 \mathrm{~ns}$ & $2.515 \mathrm{~K} \Omega$ \\
\hline
\end{tabular}




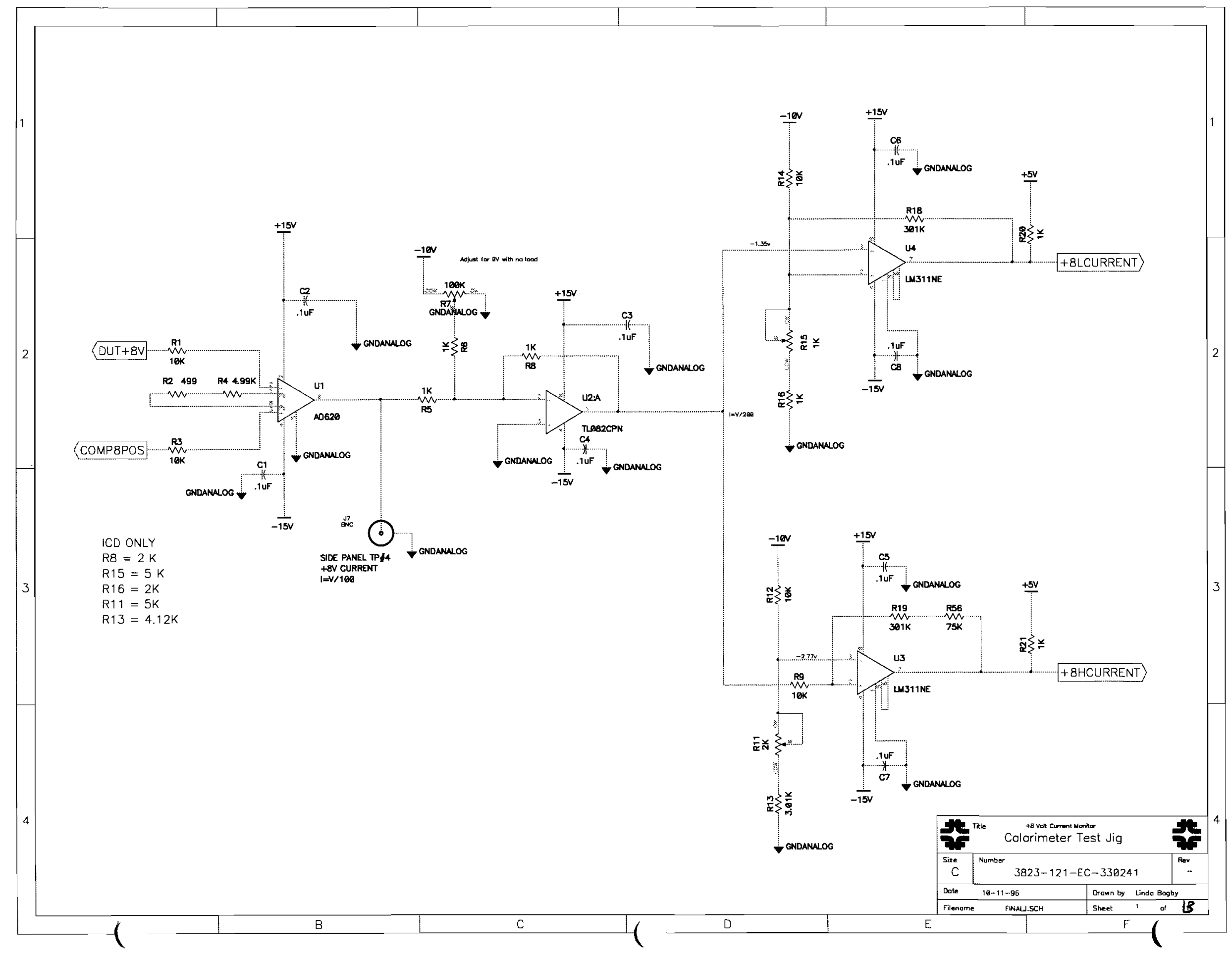




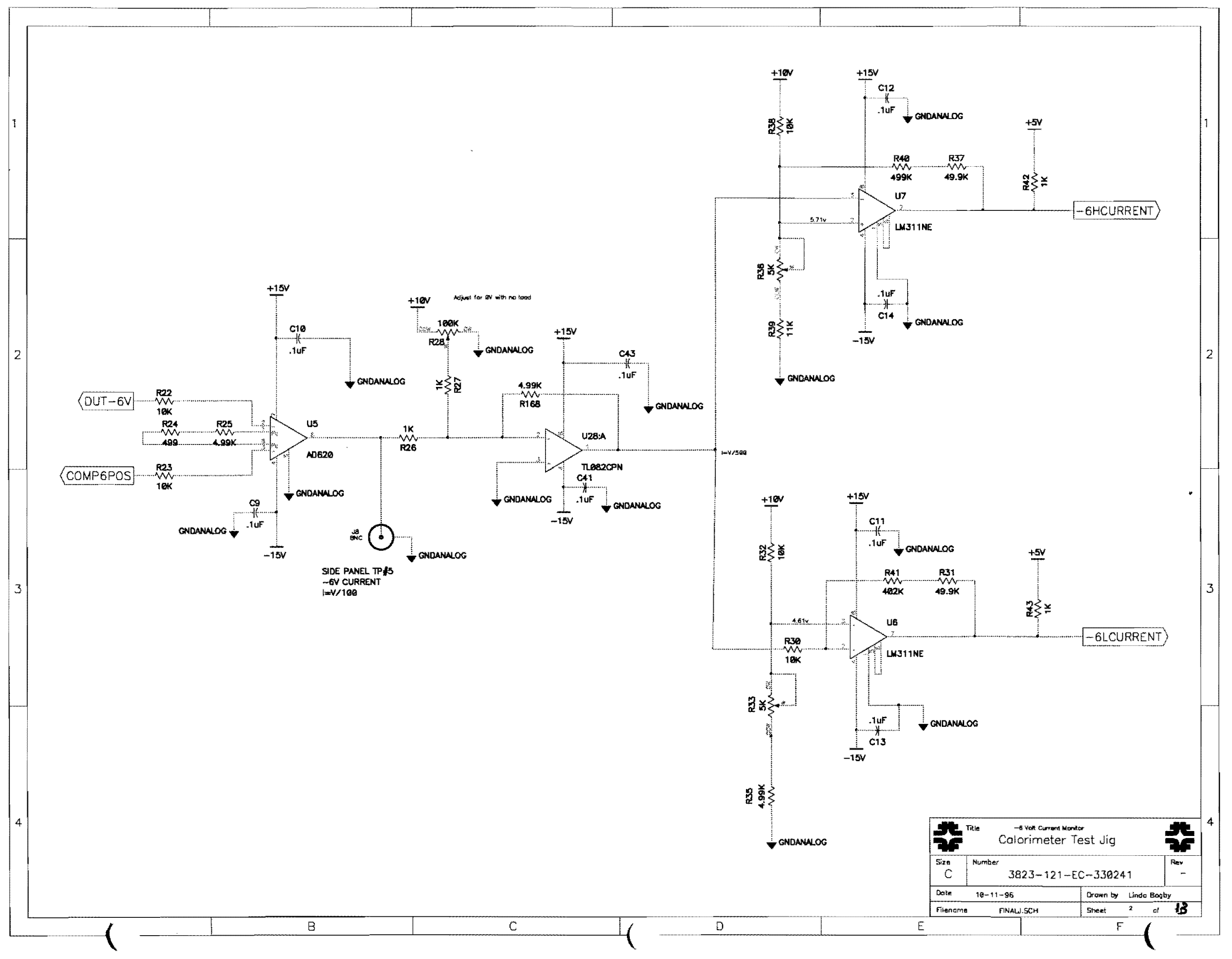




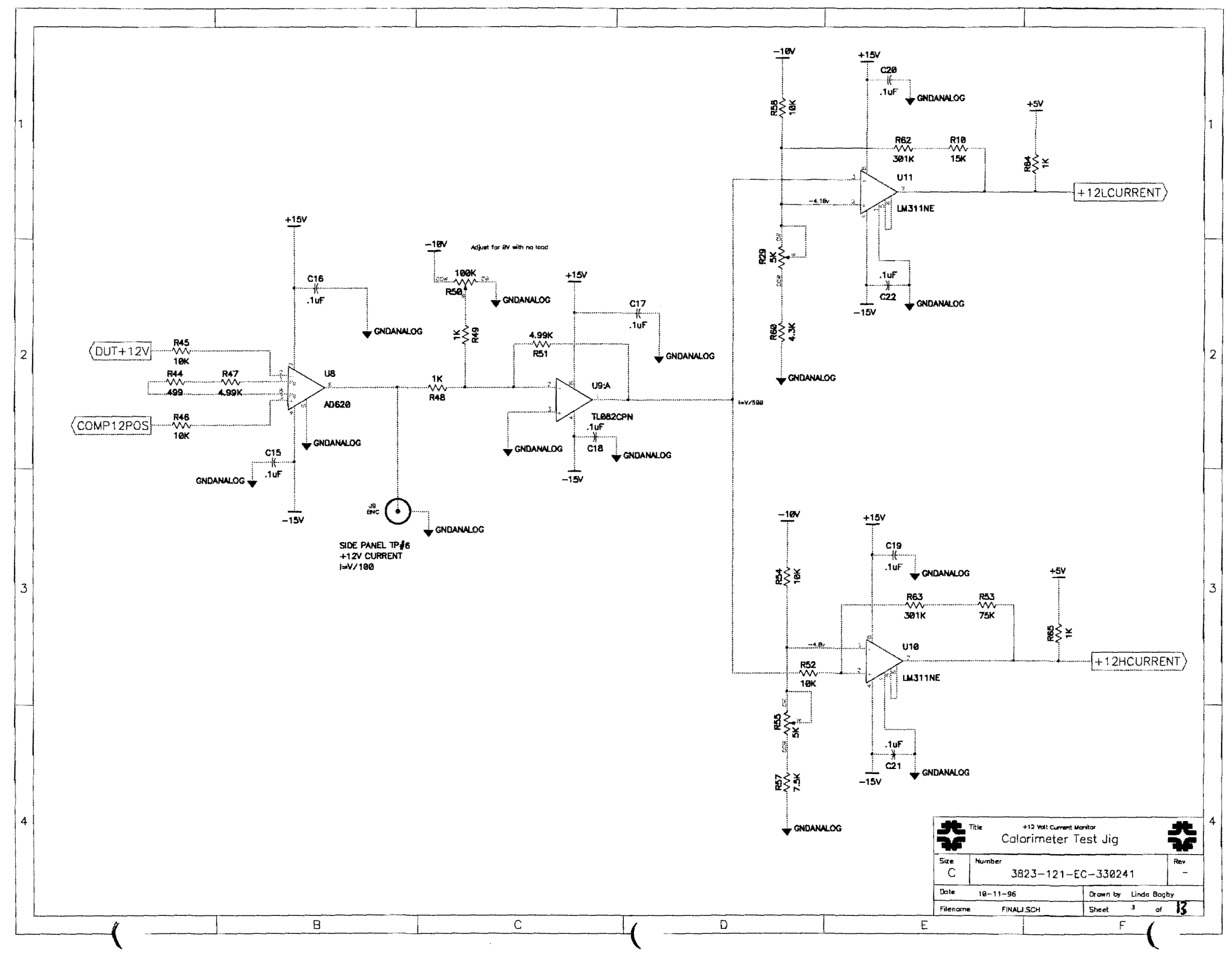




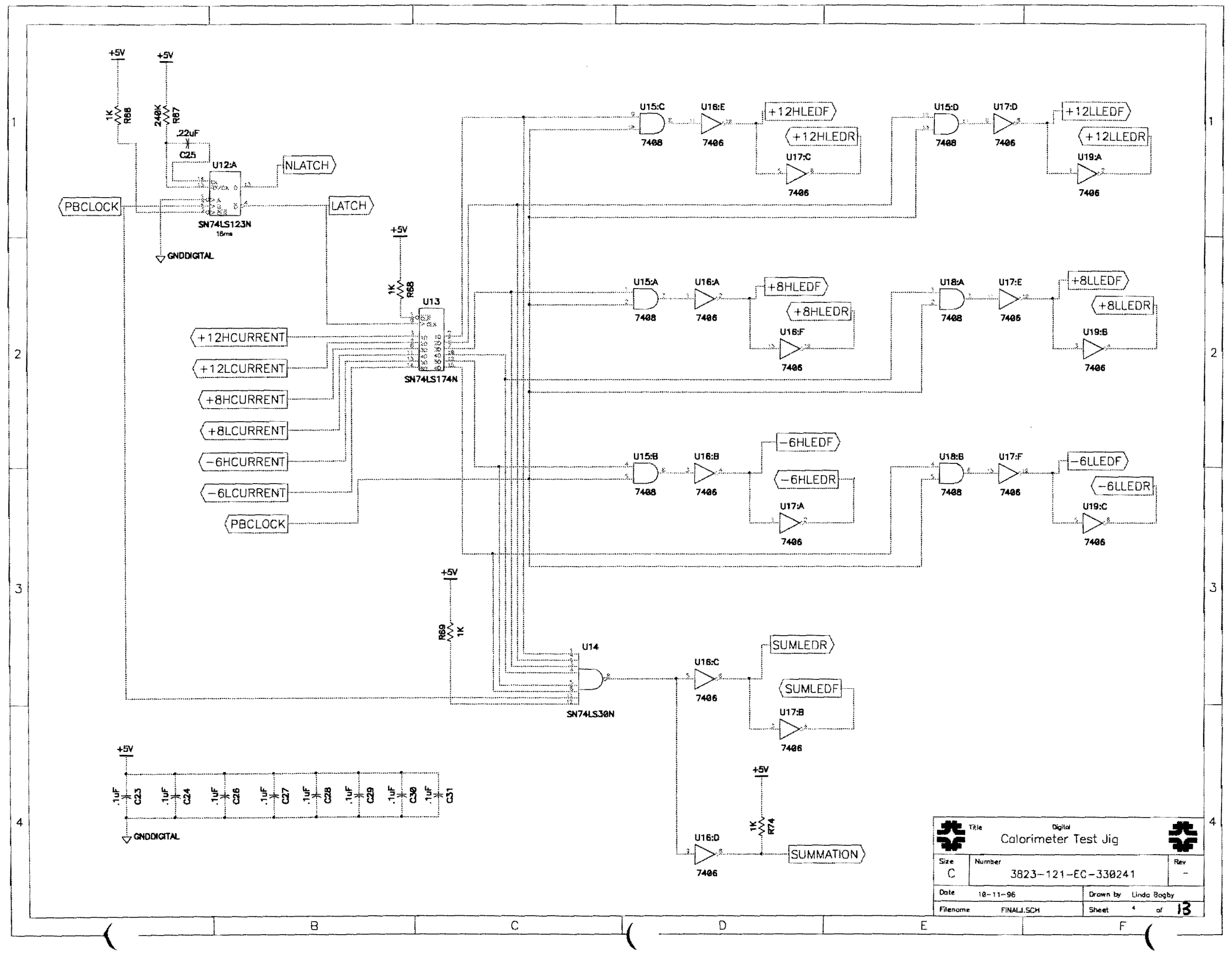




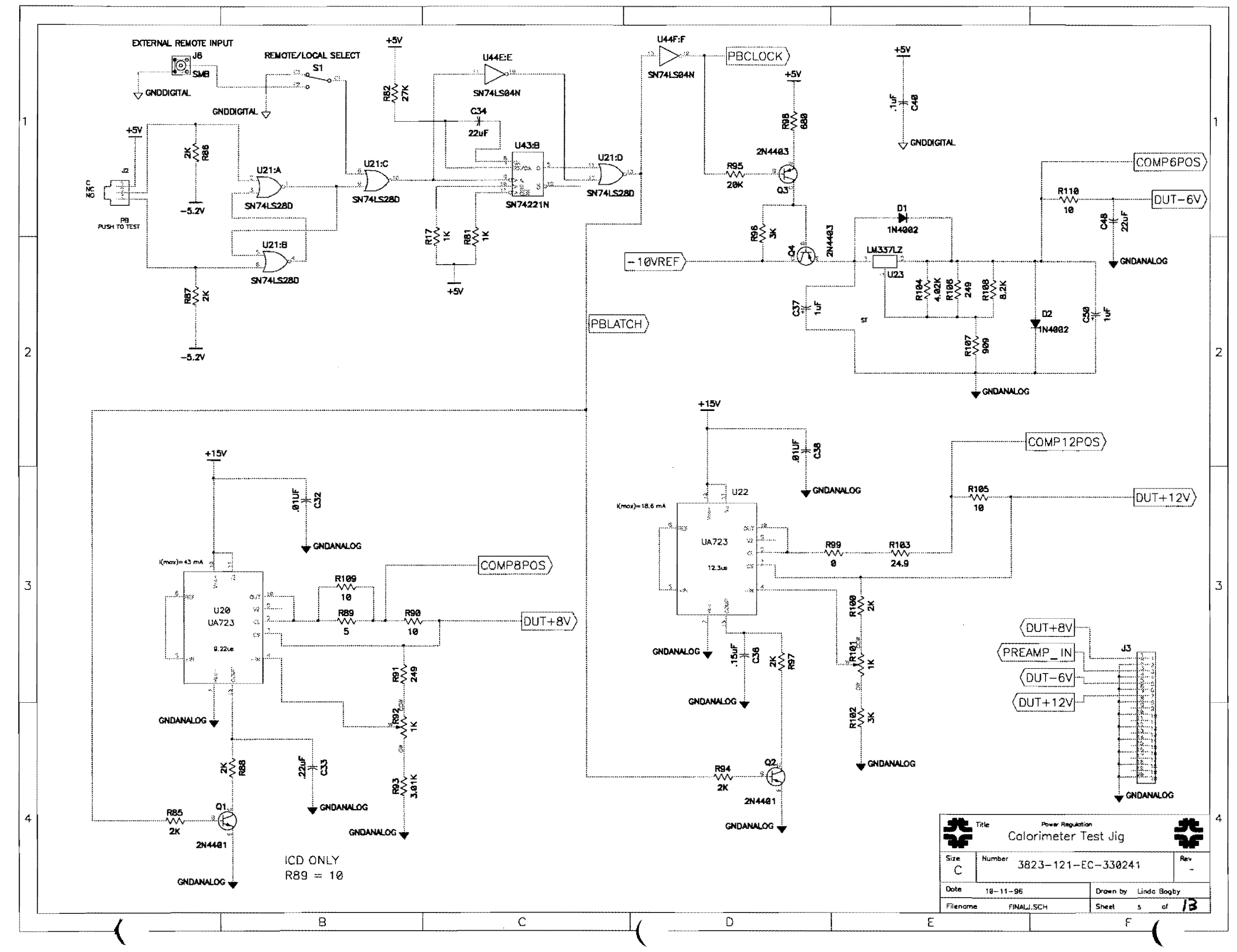




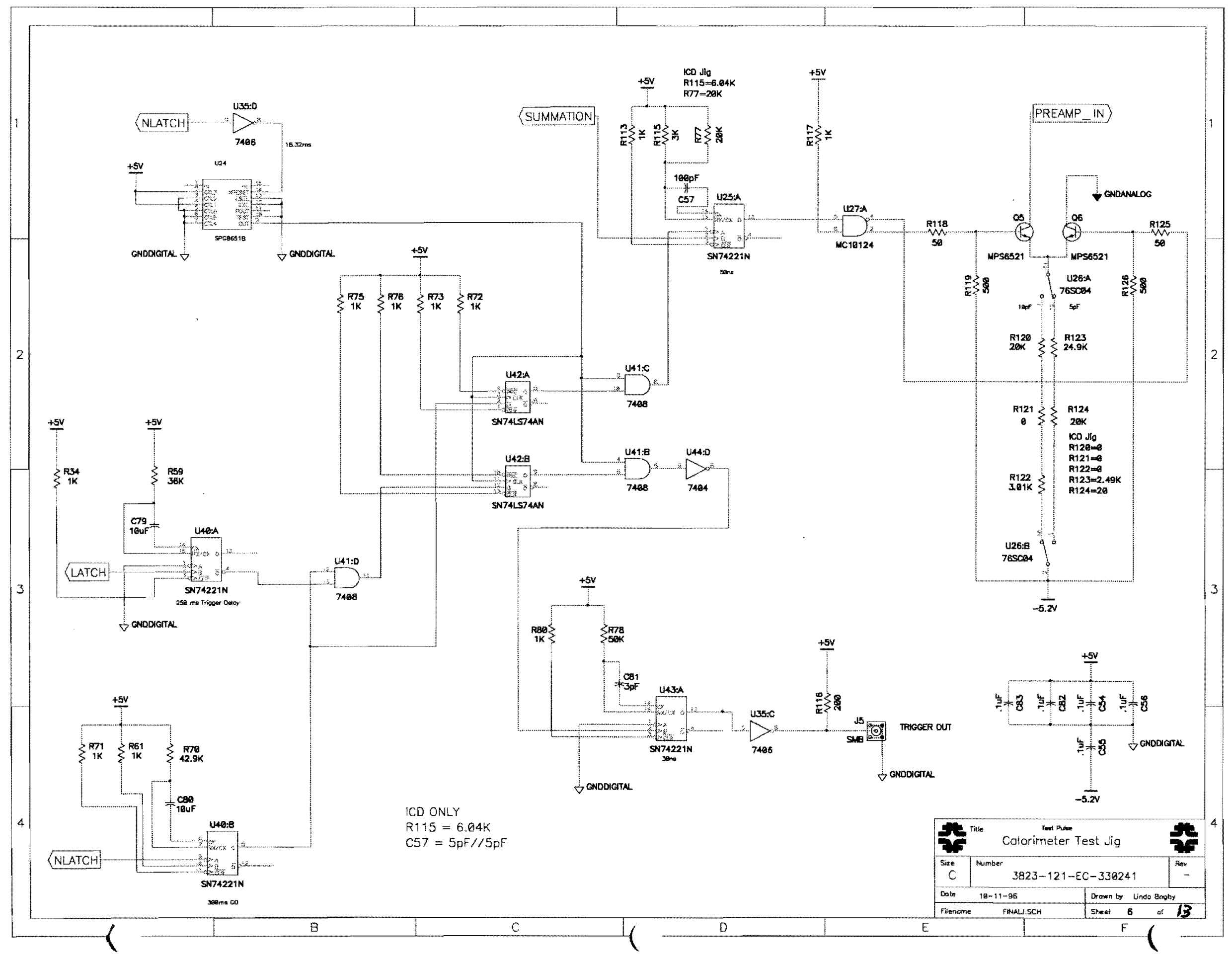




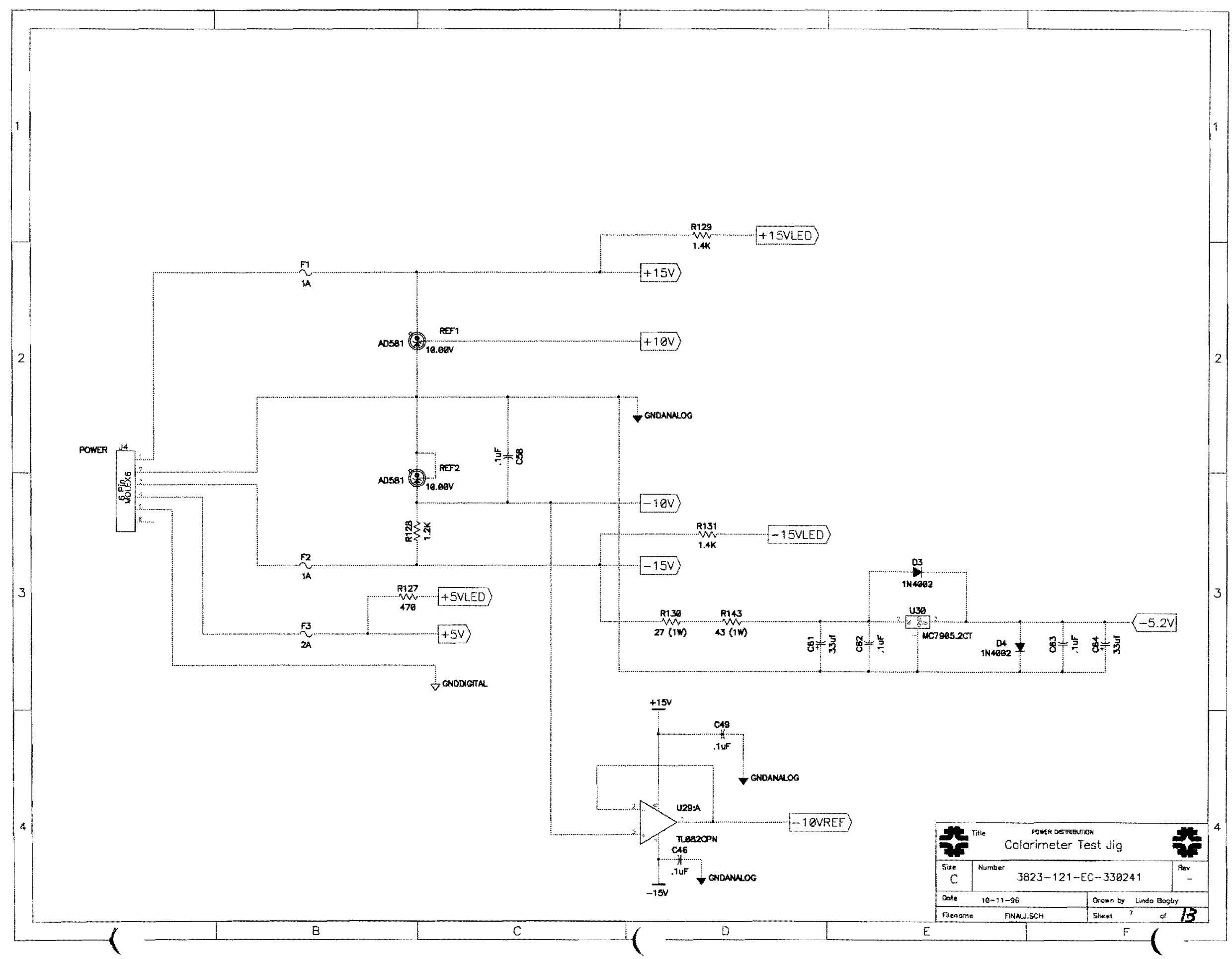




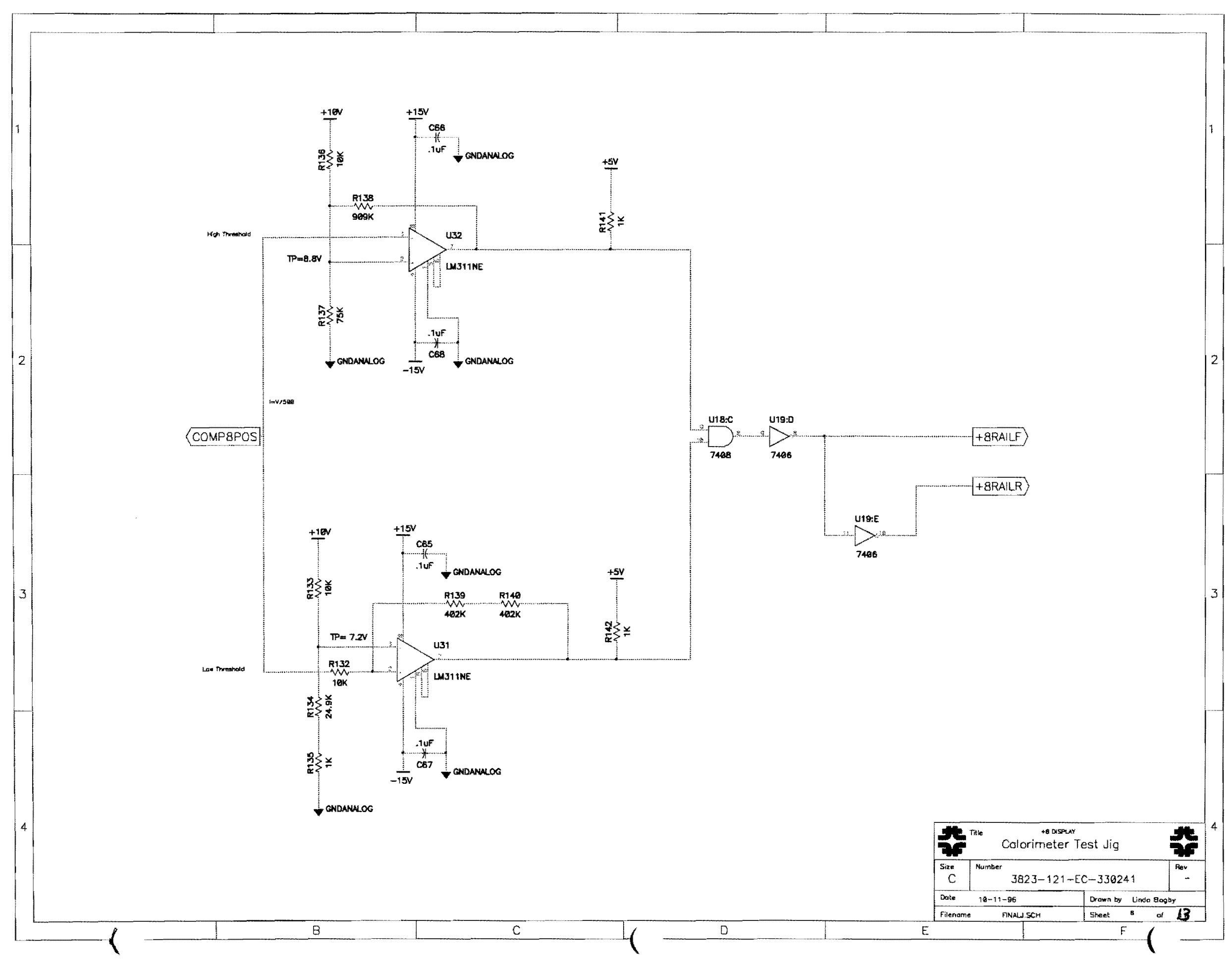




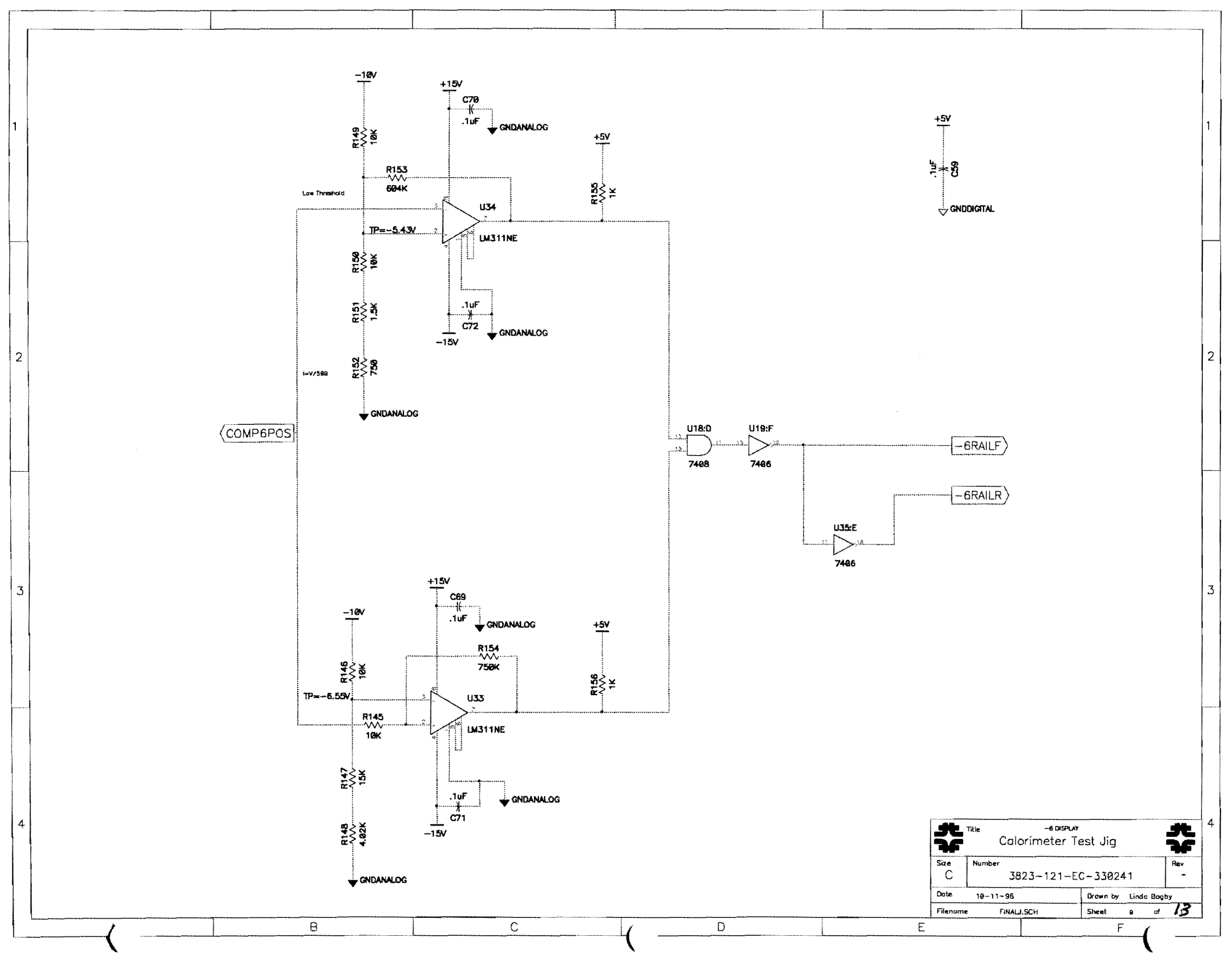




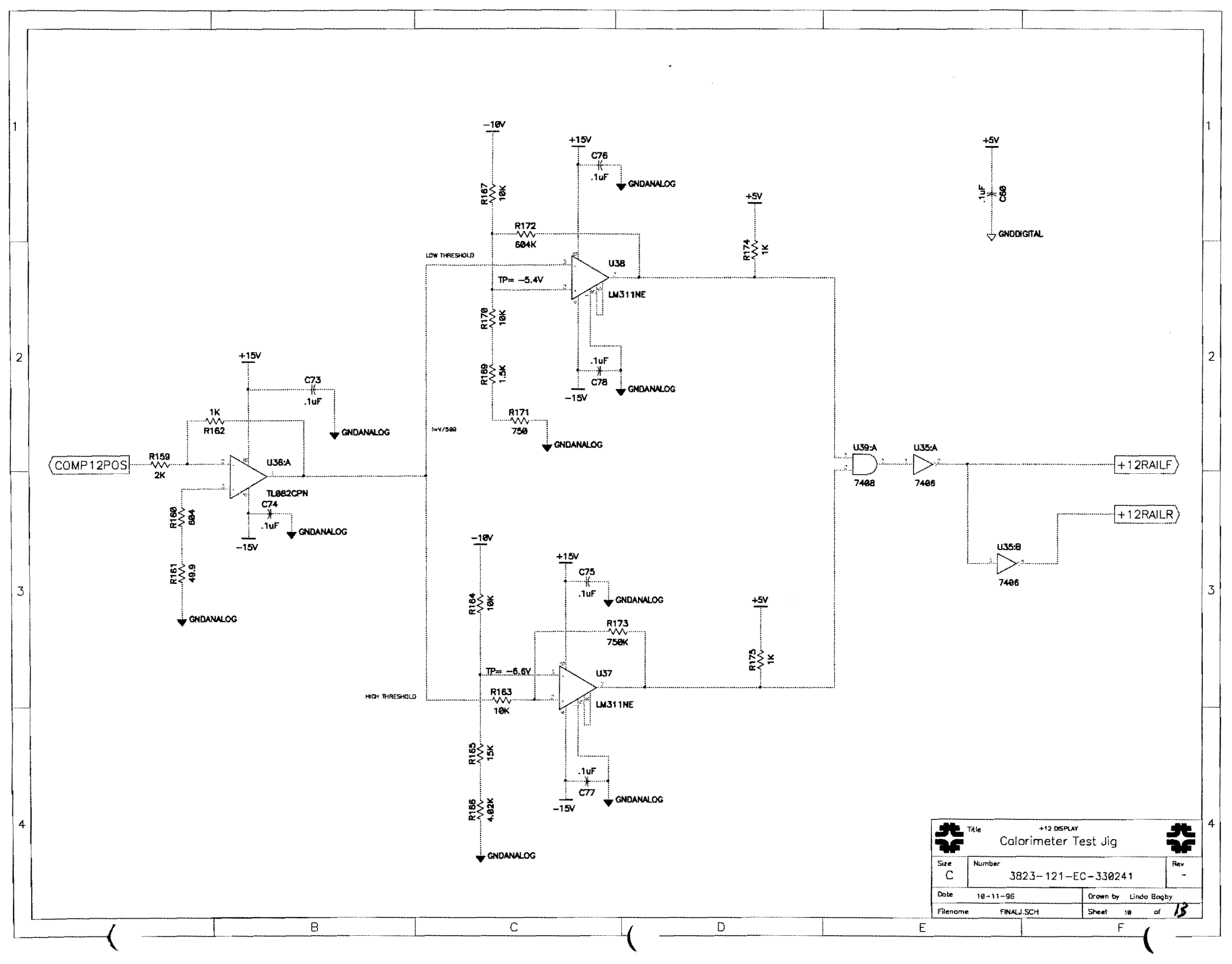




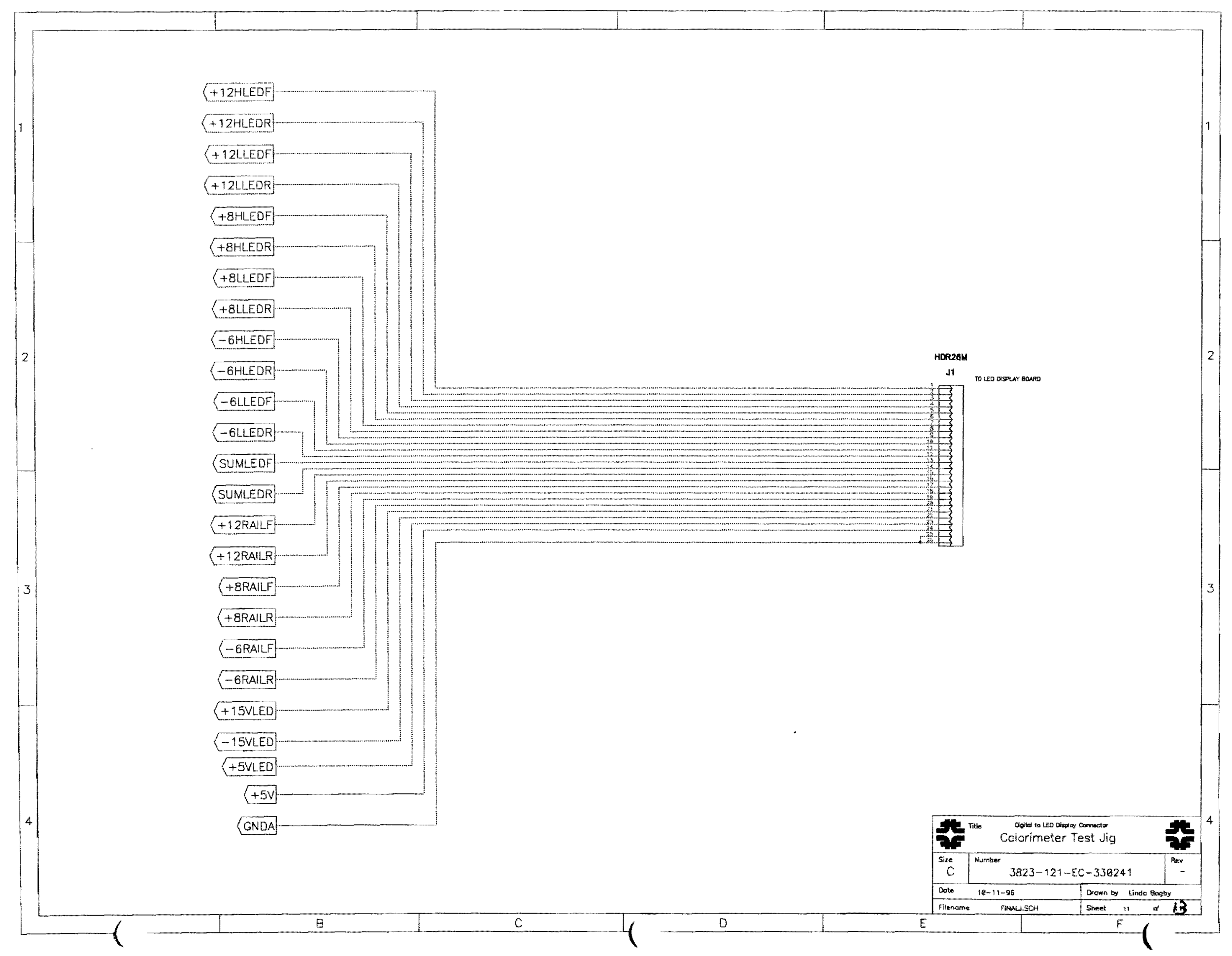




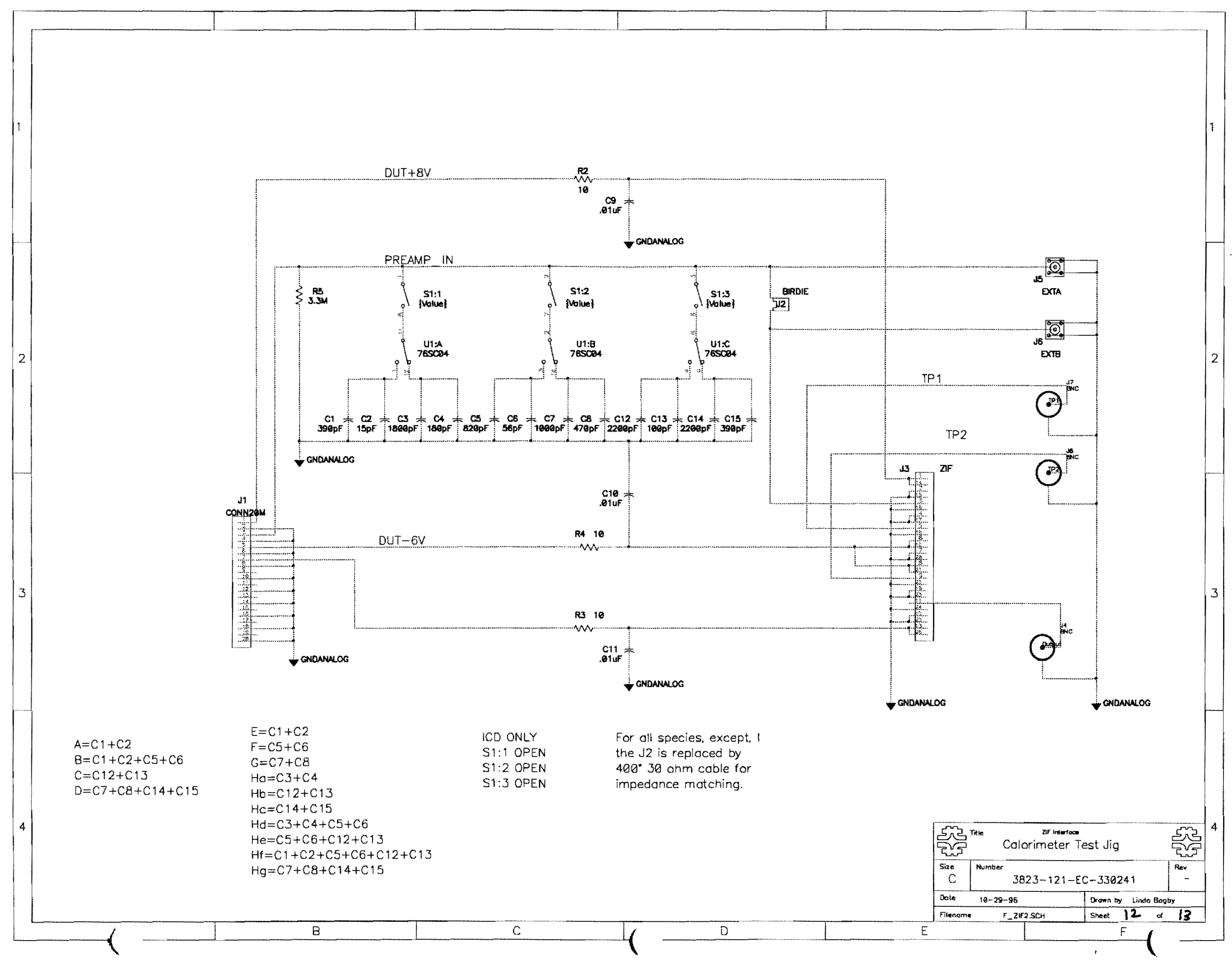




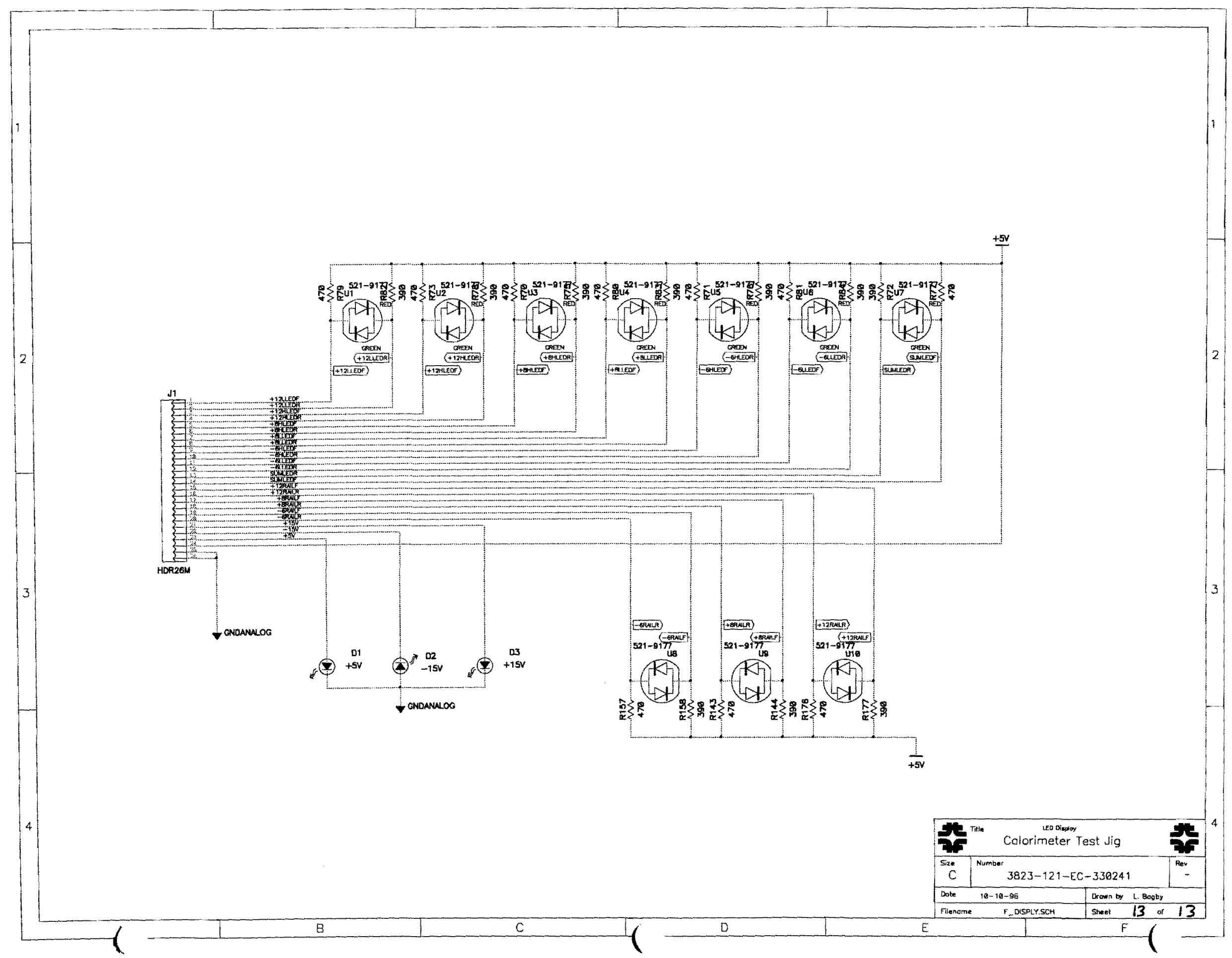

